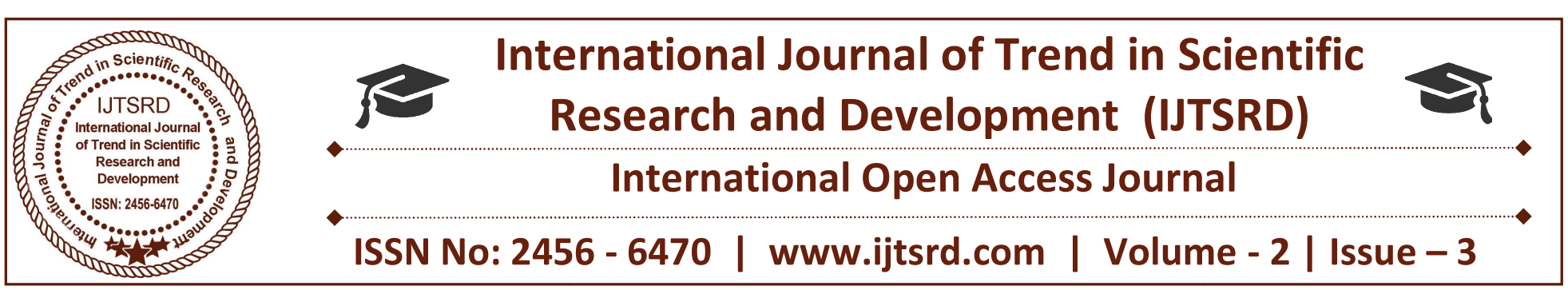

\title{
Trends in RERs and their impact on energy sector: A Review
}

\author{
Karan Sapotra \\ M.Tech Scholar, Electrical Engineering Department \\ YIET, Gadhauli, Yamunanagar, Haryana, India
}

\begin{abstract}
Renewable technologies are considered as clean sources of energy and optimal use of these resources minimize environmental impacts, produce minimum secondary wastes and are sustainable based on current and future economic and social societal needs. The potential for renewable energy resources is enormous because they can, in principle, exponentially exceed the world's energy demand; therefore, these types of resources will have a significant share in the future global energy portfolio, much of which is now concentrating on advancing their pool of renewable energy resources. Accordingly, this paper presents how renewable energy resources are currently being used, scientific developments to improve their use, their future prospects, and their deployment. Additionally, the paper represents the impact of power electronics and smart grid technologies that can enable the proportionate share of renewable energy resources. In this review cover the various configurations of the hybrid renewable energy systems for electric power generation only.
\end{abstract}

Keywords: Biomass energy; Geothermal energy; Hydropower energy; Marine energy; Solar energy; Wind energy; Smart grid

\section{INTRODUCTION}

Conventional energy sources based on oil, coal, and natural gas have proven to be highly effective drivers of economic progress. However, with the rapid depletion of conventional energy sources and increasing energy demand, worldwide primary energy consumption has grown by $1.8 \%$ in 2017 [1]. Due to certain environmental issues, many related organizations have encouraged intensive research for

more efficient and green power plants utilizing advanced technology.

Since environmental protection concerns are increasing, both clean fuel technologies and new energies are being intensively pursued and investigated. In fact, fossil fuel and renewable energy prices, social and environmental costs are moving in opposite directions and the economic and policy mechanisms needed to support the widespread dissemination of sustainable markets for renewable energy systems are rapidly evolving. It is clear that future growth in the energy sector is primarily in the new regime of renewable. Therefore, shifting to renewable energy can help us meet the dual goals of reducing greenhouse gas emissions, thereby limiting future extreme weather and climate impacts, and ensuring reliable, timely, and cost-efficient delivery of energy. Investing in renewable energy can have significant dividends for our energy security.

Renewable energies are energy sources that are continually replenished by nature and derived directly from the sun (such as thermal, photo-chemical, and photo-electric), indirectly from the sun (such as wind, hydropower, and photosynthetic energy stored in biomass), or from other natural movements and mechanisms of the environment (such as geothermal and tidal energy). Renewable energy does not include energy resources derived from fossil fuels, waste products from fossil sources, or waste products from inorganic sources [2]. Fig. 1 shows an overview of renewable energy sources $[3,4]$. Renewable energy technologies turn these natural energy sources into usable forms of energy-electricity, heat and fuels. Fig. 2 illustrates the ability of renewable energy 
sources to provide over 3000 times the current global energy needs [5].

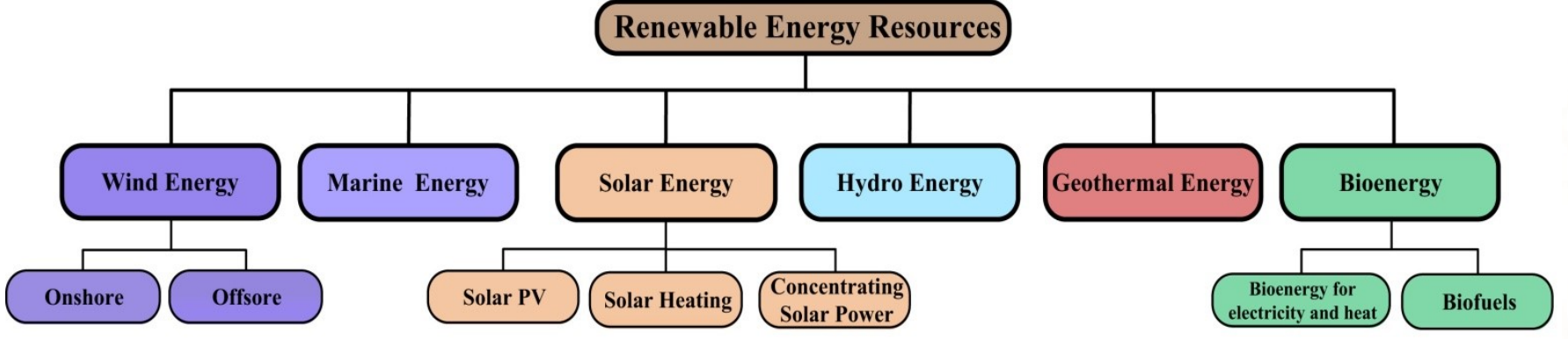

Fig. 1: Overview of renewable energy sources

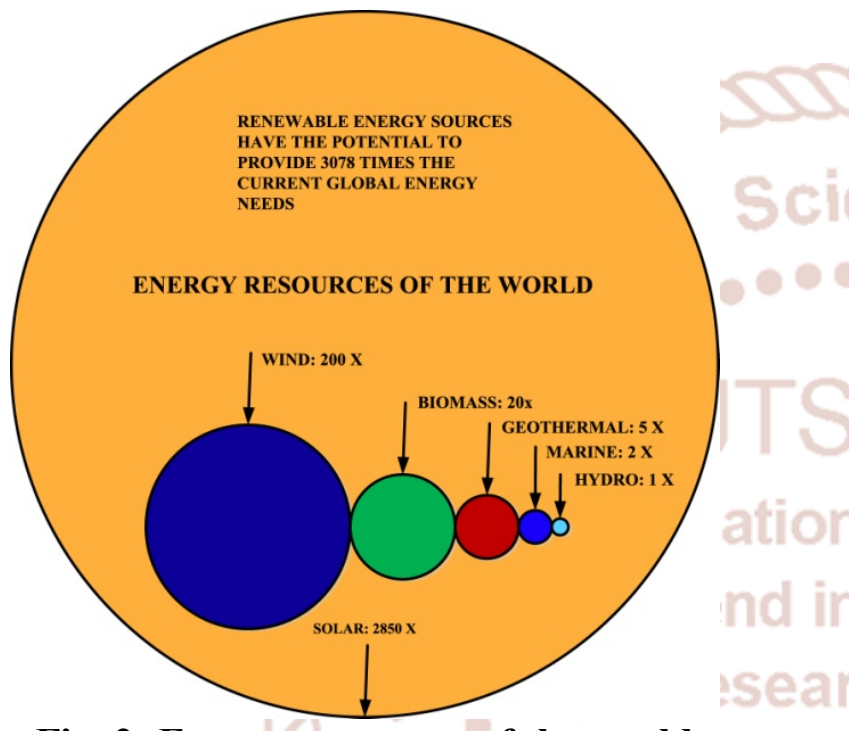

Fig. 2: Energy resources of the world

Renewable energy markets - electricity, heating and transportation - have been growing sharply over the last five years. The deployment of established technologies, such as hydro, as well as newer technologies such as wind and solar photovoltaic, has risen quickly, which has increased confidence in the technologies, reduced costs and opened up new opportunities [6].
Global electricity generation from renewable energy sources is expected to grow 2.7 times between 2010 and 2035, as indicated by Table 1 . Consumption of biofuels is projected to more than triple over the same period to reach 4.5 million barrels of oil equivalent per day (mboe/d), up from $1.3 \mathrm{mboe} / \mathrm{d}$ in 2010. Almost all biofuels are used in road transport, but the consumption of aviation biofuels will make an inroad towards 2035. The use of modern renewables to produce heat will almost double, from 337 Mtoe in 2010 to 604 Mtoe in 2035. The share of renewables in electricity generation is higher than in heat production or Transportation road, as shown in Fig. 3.

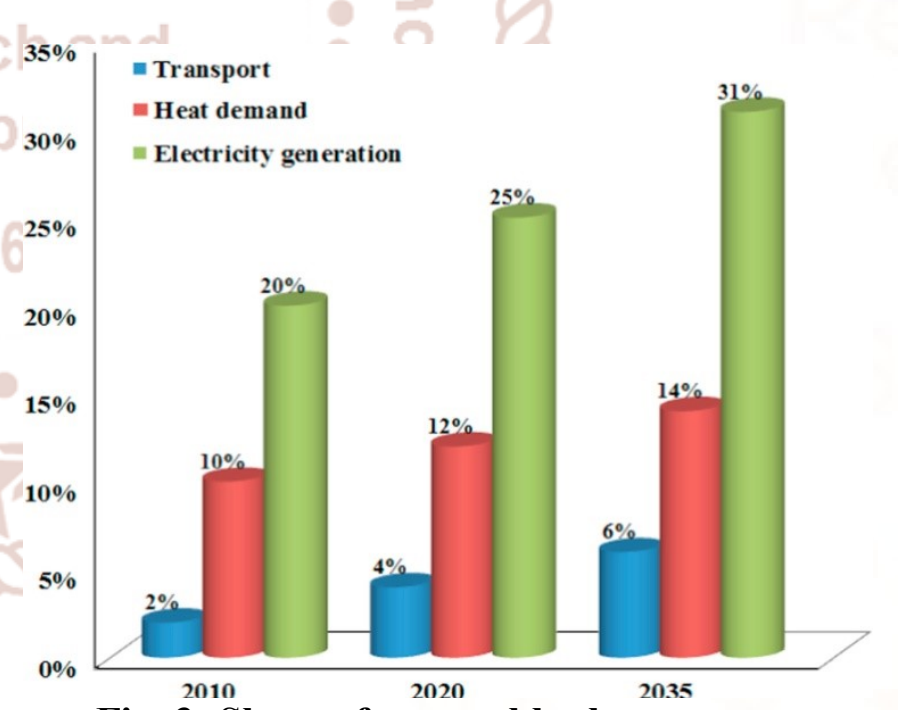

Fig. 3: Share of renewables by category

Table 1. World renewable energy use by type

\begin{tabular}{|l|l|l|l|}
\hline & $\mathbf{2 0 1 0}$ & $\mathbf{2 0 2 0}$ & $\mathbf{2 0 3 5}$ \\
\hline Electricity generation (TW h) & 4206 & 6999 & 11,342 \\
\hline Bioenergy & 331 & 696 & 1,487 \\
\hline Hydro & 3431 & 4513 & 5,677 \\
\hline Wind & 342 & 1272 & 2,681 \\
\hline Geothermal & 68 & 131 & 315 \\
\hline Solar PV & 32 & 332 & 846 \\
\hline Concentrating solar power & 2 & 50 & 278 \\
\hline
\end{tabular}


International Journal of Trend in Scientific Research and Development (IJTSRD) ISSN: 2456-6470

\begin{tabular}{|l|l|l|l|}
\hline Marine & 1 & 5 & 57 \\
\hline Share of total generation & $20 \%$ & $25 \%$ & $31 \%$ \\
\hline Heat demand (Mtoe) & 337 & 447 & 604 \\
\hline Industry & 207 & 263 & 324 \\
\hline Buildings and agriculture & 131 & 184 & 280 \\
\hline Share of total production & $10 \%$ & $12 \%$ & $14 \%$ \\
\hline Biofuels (mboe/d) & 1.3 & 2.4 & 4.5 \\
\hline Road transport & 1.3 & 2.4 & 4.4 \\
\hline Aviation & - & - & 0.1 \\
\hline Share of total transport & $2 \%$ & $4 \%$ & $6 \%$ \\
\hline
\end{tabular}

The goal of the paper is to present an overview of the different types of renewable energy resources, their current and future states, their share in different end use applications, and their benefits, growth, investment and deployment. Furthermore, power electronics and smart grid will be discussed as enabling technologies for different renewable energy resources.

\section{DESCRIPTION OF RENEWABLE ENERGY SOURCES}

\subsection{Biomass energy}

Biomass is the term used for all organic material originating from plants, trees and crops, and is essentially the collection and storage of the sun's energy through photosynthesis. Biomass energy (bioenergy) is the conversion of biomass into useful forms of energy such as heat, electricity and liquid fuels (biofuels). Biomass for bioenergy comes either directly from the land, such as from dedicated energy crops, or from residues generated in the processing of crops for food or other products [8-10].

Biomass energy is renewable and sustainable, but shares with fossil fuels many characteristics. While biomass can be directly burned to obtain energy, it can also serve as a feedstock to be converted to various liquid or gas fuels (biofuels). Biofuels can be transported and stored, and allow for heat and power generation on demand, which is essential in an energy mix with a high dependence on intermittent sources such as wind. These similarities account for the major role biomass is expected to play in future energy scenarios [11]. Therefore, a recently emerging strategy is to develop biorefinery and biotransformation technologies to convert biomass feedstock into clean energy fuels.

\subsection{Geothermal energy}

Geothermal energy is a powerful and efficient way to extract renewable energy from the earth by natural processes. This can be performed on a small scale to provide heat for a residential unit by using a geothermal heat pump, or on a large scale for energy production through a geothermal power plant. Geothermal power is considered a cost effective, reliable, and environmentally friendly energy source [15].

Geothermal energy resources consist of thermal energy from the earth's interior stored in both rock and trapped steam or liquid water. Geothermal systems occur in different geological environments where the temperatures and depths of the reservoirs vary accordingly. Many high-temperature hydrothermal systems (greater than $180{ }^{\circ} \mathrm{C}$ ) are associated with recent volcanic. Intermediatetemperature (between 100 and $180{ }^{\circ} \mathrm{C}$ ) and lowtemperature (less than $100^{\circ} \mathrm{C}$ ) systems are also found in continental settings, where above-normal heat production through radioactive isotope decay increases terrestrial heat flow or where aquifers are charged by water heated through circulation along deeply penetrating fault zones. Under appropriate conditions, high, intermediate and low temperature geothermal fields can be utilized for both power generation and the direct use of heat $[16,17]$.

Geothermal energy sources are classified as hydrothermal systems, conductive systems and deep aquifers. Hydrothermal systems include liquid and vapor dominated types. Conductive systems include hot rock and magma over a wide range of temperatures, and deep aquifers contain circulating fluids in porous media or fracture zones at depths typically greater than $3 \mathrm{~km}$, though they lack a localized magmatic heat source. 
Geothermal energy resource utilization technologies can be grouped under types for electrical power generation, direct use of heat, or combined heat and power in cogeneration applications. Geothermal heat pump (GHP) technologies are a subset of direct use. Currently, the only commercially exploited geothermal systems for power generation and direct use are hydrothermal.

\subsection{Hydropower energy}

Hydropower is a power that is derived from the energy of moving water. Flowing water creates energy that can be captured and converted into electricity by using turbines. The most prevalent form of hydropower is dams, although newer forms harnessing wave and tidal power are becoming more common.

Hydropower is generated from water moving in the hydrological cycle, which is driven by solar radiation. It is the flow of water in rivers, driven by the force of gravity to move from higher to lower elevations that can be used to generate hydropower. Hydropower plants (HPP) span a very large range of scales, from a few watts to several GW. The largest projects are Itaipu in Brazil with 14,000 MW and Three Gorges in China with 22,400 MW, both producing between 80 to $100 \mathrm{TW} \mathrm{h/yr}$. Hydropower projects are always sitespecific, and, thus, designed according to the river system they inhabit. Historical, regional hydropower generation from 1965 to 2012 is shown in Fig. $9[22,23]$. Five countries make up more than half of the world's hydropower production: China, Brazil, Canada, USA and Russia [24]. Fig. 10 illustrates the top ten countries in hydropower generation in 2012 . Over the next decade, hydropower should increase by approximately $180 \mathrm{GW}$ of installed capacity if projects currently under construction proceed as planned. This increase corresponds to roughly onequarter of the currently installed capacity. One-third of this increase will come from China alone; furthermore, Turkey will see the largest capacity additions. Brazil and India also have a large capacity under construction.

\subsection{Marine energy}

The renewable marine (ocean) energy comes from six distinct sources: waves, tidal range, tidal currents, ocean currents, ocean thermal energy conversion and salinity gradients, each with different origins and requiring different technologies for conversion. All ocean energy technologies, except tidal barrages, are conceptually undergoing intensive research and development, or are in the pre-commercial prototype and demonstration stage. The theoretical potential for ocean energy technologies has been estimated at 7400 $\mathrm{EJ} / \mathrm{yr}$, exceeding current and future human energy needs. Relatively few assessments have been conducted on the technical potential of the various ocean energy technologies and such potentials will vary based on future technological development [26].

\subsection{Solar energy}

Solar energy generation involves the use of the sun's energy to provide hot water via solar thermal systems or electricity via solar photovoltaic (PV) and concentrating solar power (CSP) systems. These technologies are technically well proven with numerous systems installed around the world over the last few decades.

\subsubsection{Photovoltaic}

Solar photovoltaic (PV) systems directly convert solar energy into electricity. The basic building block of a PV system is the PV cell, which is a semiconductor device that converts solar energy into direct-current electricity. PV cells are interconnected to form a PV module, typically up to 50 to $200 \mathrm{~W}$. The PV modules, combined with a set of additional application-dependent system components (e.g., inverters, batteries, electrical components, and mounting systems), form a PV system. PV systems are highly modular, i.e., modules can be linked together to provide power ranging from a few watts to tens of megawatts.

\subsubsection{Concentrating solar power}

Concentrating solar power (CSP) technologies produce electricity by concentrating direct-beam solar irradiance to heat a liquid, solid or gas that is then used in a downstream process for electricity generation. Large-scale CSP plants most commonly concentrate sunlight by reflection, as opposed to refraction with lenses. Concentration is either to a line (linear focus) as in trough or linear fresnel systems or to a point (point focus) as in central-receiver or dish systems. CSP applications range from small distributed systems of tens of $\mathrm{kW}$ to large centralized power stations of hundreds of MW. The earliest commercial CSP plants were the $354 \mathrm{MW}$ of solar electric generating stations in California that continue to operate commercially today. 


\subsubsection{Solar thermal heating and cooling}

Solar heating and cooling technologies collect thermal energy from the sun and use this heat to provide hot water, space heating, cooling, and pool heating for residential, commercial, and industrial applications. By the end of 2017, global solar thermal capacity in operation reached an estimated 282 GWth. Global capacity of glazed water collectors reached 255 GWth. The top countries for total capacity in operation were China, Germany, Turkey, Brazil and India.

\subsection{Wind energy}

Wind power is defined by the conversion of wind energy by wind turbines into a useful form, such as using wind turbines to make electricity, wind mills for mechanical power, wind pumps for pumping water or drainage, or sails to propel ships. The first wind turbines for electricity generation were developed at the beginning of the 20th century. The technology has gradually improved since the early 1970s. By the end of the 1990s, wind energy has re-emerged as one of the most important sustainable energy resources.

Generating electricity from the wind requires that the kinetic energy of moving air be converted to mechanical and then electrical energy, thus challenging the industry to design cost effective wind turbines and power plants to perform this conversion. The amount of kinetic energy in the wind that is theoretically available for extraction increases with the cube of the wind speed. However, a turbine only captures a fraction of that available energy $(40-50 \%)$, so wind turbine design has focused on maximizing energy capture over the range of wind speeds experienced by wind turbines, while seeking to minimize the cost of wind energy tacking all parameters in account. To minimize cost, wind turbine design is also motivated by a desire to reduce materials usage while continuing to increase turbine size, increase component and system reliability, and improve wind power plant operations.

\section{POWER ELECTRONICS RENEWABLE ENERGY SYSTEMS}

IN

Power electronics technology has gained significant maturity after several decades of dynamic evolution of power semiconductor devices, converters, pulse width modulation (PWM) techniques, electrical machines, motor drives, advanced controls, and simulation techniques. Power electronics deals with the conversion and control of electrical power with the help of power semiconductor devices that operate in switching mode; therefore, the efficiency of power electronic apparatus may approach as high as 98$99 \%$. With the advancement of technology, the lowered cost of power electronics, the reduced size, and the improved performance, power electronics applications are proliferating in industrial, commercial, residential, aerospace, military, utility, and transportation systems. In addition, the impact of power electronics in renewable energy systems is significant in solving our energy shortage because it enable the efficient generation, use, and distribution of electrical energy by substantially improving energy conversion efficiency. Indeed, power electronics are needed in almost all kinds of renewable energy systems. It is used both for controlling the renewable source and for interfacing to the load, which can be grid-connected or working in stand-alone mode. The power may flow in both directions, of course, depending on the topology and applications. Power electronics converters configurations interfacing different renewable energy sources will be presented in the following subsections.

\section{RENEWABLE ENERGY: BENEFITS, GROWTH, INVESTMENT AND DEPLOYMENT}

Renewable energy can provide a host of benefits to society, as shown in Fig. 4. In addition to the reduction of carbon dioxide (CO2) emissions, governments have enacted renewable energy (RE) policies to meet a number of objectives including the creation of local environmental and health benefits; facilitation of energy access, particularly for rural areas; advancement of energy security goals by diversifying the portfolio of energy technologies and resources; and improving social and economic development through potential employment opportunities. 
International Journal of Trend in Scientific Research and Development (IJTSRD) ISSN: 2456-6470

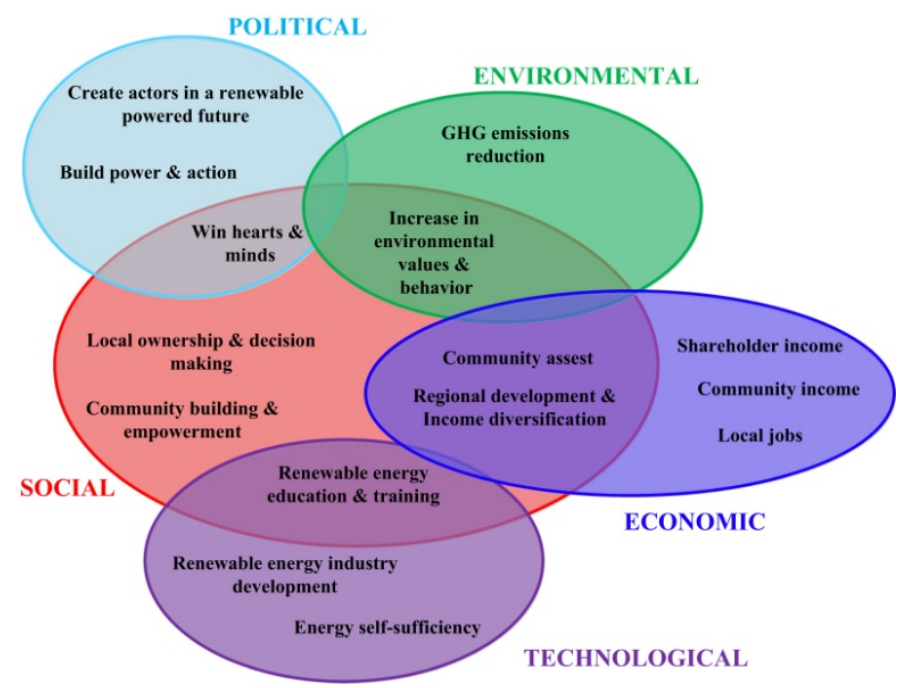

Fig. 4: Global benefits of renewable energies production

\section{CONCLUSIONS}

Due to the shortage of inexhaustible resources, and environmental problems caused by the emissions, traditional power generation based on fossil fuels are generally considered to be unsustainable in the long term. As a result, many efforts are made worldwide for introducing more renewable energies in the energy mix. Renewable energy resources are innovative options for electricity generation and their potential is enormous as they can, in principle, meet the world's energy demand many times over. This paper presents an up-to-date and detailed current status and future projection of major renewable energy resources, as well as their benefits, growth, investment and deployment. In addition, the role of power electronics converters as enabling technology for using different renewable energy resources is illustrated. Furthermore, integration of renewable energy resources into smart grid system, keeping in mind all challenges, will help in meeting ever-increasing electric energy demands effectively.

\section{REFERENCES}

1. BP Statistical Review of World Energy, 〈bp.com/statisticalreview〉; 2017

2. 〈http://www.treia.org〉 [accessed on 6/3/2018].

3. Brown A, müller S, Dobrotková Z. Renewable energy: markets and prospects by technology. Int Energy Agency Inf Paper 2011.

4. Bull SR. Renewable energy today and tomorrow. Proc IEEE 2001;89(8).
5. RE-thinking 2050, 〈www.erec.org〉.

6. Deploying Renewables 2017, 〈www.iae.org〉.

7. World Energy Outlook 2016, 〈www.iae.org〉.

8. Srirangan K, Akawi L, Moo-Young M, Chou CP. Towards sustainable production of clean energy carriers from biomass resources. Appl Energy 2012;100:172-86 (December).

9. Sriram N, Shahidehpour M. Renewable biomass energy. In: IEEE power engineering society general meeting, vol. 1; 12-16 June 2005. p. 612617.

10. Reddy BY, Srinivas T. Biomass based energy systems to meet the growingenergy demand with reduced global warming: role of energy and exergy analyses. In: International conference on energy efficient technologies for sustainability (ICEETS); 10-12 April 2013. p. 18-23.

11. Hall DO, Scrase JI. Will biomass be the environmentally friendly fuel of the future? Biomass Bioenergy 1998;15(4/5):357-67.

12. Klass DL. Biomass for renewable energy and fuels, Encyclopedia of energy, vol. 1, p. 193-212.

13. Ruiz JA, Juárez MC, Morales MP, Muñoz P, Mendívil MA. Biomass gasification for electricity generation: review of current technology barriers. Renewable Sustainable Energy Rev 2013;18:17483.

14. Biomass for Power Generation, June 2017, 〈www.irena.org .

15. Hammons TJ. Geothermal power generation worldwide. In: 2003 IEEE Bologna power tech conference proceedings; 23-26 June 2003.

16. Fridleifsson IB. Geothermal energy for the benefit of the people, Renewable Sustainable Energy Rev, 5, 299-312.

17. Yan Q, Wang A, Wang G, Yu W, Chen Q. Resource evaluation of global geothermal energy and the development obstacles. In: 2010 International conference on advances in energy engineering; 19-20 June 2010. p. 115-119.

18. Sheth S , Shahidehpour M. Geothermal energy in power systems. In: IEEE power engineering society general meeting, vol. 2; 10-10 June 2004. p. $1972-1977$.

19. Geothermal: international marker overview report; May 2010, 〈www.GEO-energy.org〉. 
20. 〈http://www.endeavorscorp.com $\rangle$.

21. Renewable Energy Sources and Climate Change Mitigation.

22. Statistical Review of World Energy 2013, www.bp.com.

23. British petroleum statistical review of world energy. British Petroleum, London, UK; 2010. p. 50 .

24. Wang Q, Yang T. Sustainable hydropower development: international perspective and challenges for China. In: 2011 International conference on multimedia technology (ICMT); 26-28 July 2011. p. 5564-5567.

25. Hydropower and the environment: present context and guidelines for future action; May 2000, IEA Hydropower 〈http://www.ieahydro.org/ reports/HyA3S5V2.pdf).

26. Bhuyan GS. World-wide Status for Harnessing Ocean Renewable Resources. In: 2010 IEEE power and energy society general meeting; 25-29 July 2010 . 